\section{CAG Educational Needs Assessment Report}

Ronald Bridges MD FRCPC

Chair, CAG Education Committee

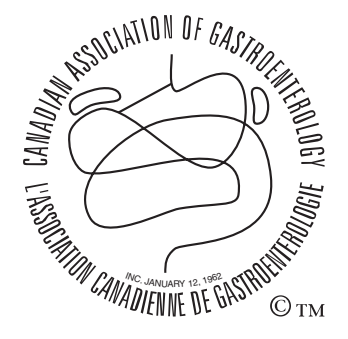

En français voir page 117
$\mathrm{T}^{\mathrm{h}}$ he annual survey of Canadian Association of Gastroenterology (CAG) members' educational needs was conducted online during May and June 2004. Sixtyeight members $(7.4 \%)$ completed the needs assessment. It was determined that the topic most in demand for future educational events, similar to previous years, was inflammatory bowel disease (IBD) from the clinical perspective. Also highly rated were the clinical topics of endoscopy, upper gastrointestinal bleeding and viral hepatitis. Educational materials were by far judged to be the most valuable component of exhibit areas $(91 \%)$, and $43 \%$ reported repeated use of the online CAG Interactive Lecture Series. Additionally, $90 \%$ of respondents agreed that they would use an online Canadian atlas of endoscopy if available. However, given the very small proportion of CAG members completing the needs assessment, results should be interpreted with caution.

The purpose of the CAG needs assessment was to provide guidance to the Executive and the CAG Education Committee on areas of greatest educational need. Conducting a needs assessment is a requirement for accreditation of educational events according to the Royal College of Physicians and Surgeons of Canada accreditation criteria.

\section{METHODS}

The Education Committee consists of Drs Janice Barkey, Jamie Gregor, John Fardy, Dana Farina, Marty Fishman, Terrence Moore, Alaa Rostom, Richard Schreiber and Connie Switzer. The needs assessment was the same as that used in 2003, apart from the addition of two questions. Members were requested by e-mail to visit the CAG Web site to complete the simple 'tick box' survey. Data were compiled and analyzed at the CAG National Office.

The needs assessment included four sections. The first section collected basic demographic information; the second questioned members on their interest in topics for educational events from a basic science, clinical and pediatric perspective; the third examined needs for the exhibit area; and the fourth section explored actual use of the online Interactive Lecture Series and potential use, if available, of an online Canadian atlas of endoscopy.

Respondents were asked to rate their interest in 33 potential topics for educational events using a scale of 1 to 7 , where $1=$ no interest and $7=$ extremely interested. For exhibits, respondents selected those items of greatest value to them. The actual and anticipated use of the Interactive Lecture Series and an online atlas of endoscopy, respectively, were assessed by frequency category.

\section{RESULTS}

Sixty-eight members (7.4\%) of the solicited (917 with e-mail addresses) membership completed the needs assessment.

\section{Demographics}

Of the respondents, $72 \%$ were men and $28 \%$ were women. Regarding education, $82 \%$ were MDs, approximately $4 \%$ were $\mathrm{MD} / \mathrm{PhDs}$, approximately $4 \%$ were $\mathrm{PhDs}$ and $9 \%$ held another degree. The majority of respondents (68\%) were predominantly hospital- rather than community-based. Most replies were from Ontario members (34\%), followed by Alberta (18\%), Quebec (16\%) and British Columbia $(13 \%)$, with responses distributed roughly in proportion to provincial population.

The CAG is proud to acknowledge its Benefactor Corporate Sponsors:

Abbott Laboratories Ltd. Janssen-Ortho Inc.
AstraZeneca Canada Inc. Pfizer Canada Inc.
Axcan Pharma Inc. Schering Canada Inc. 


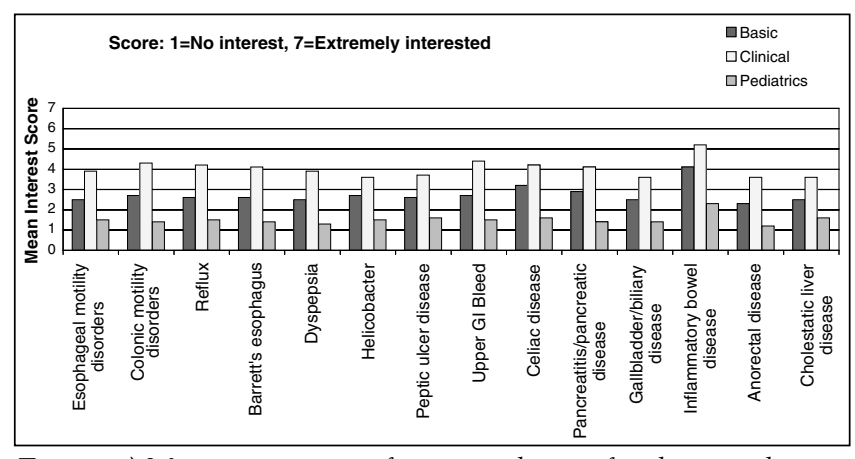

Figure 1) Mean interest score for potential scientific educational topics (topics 1 to 14). GI Gastrointestinal

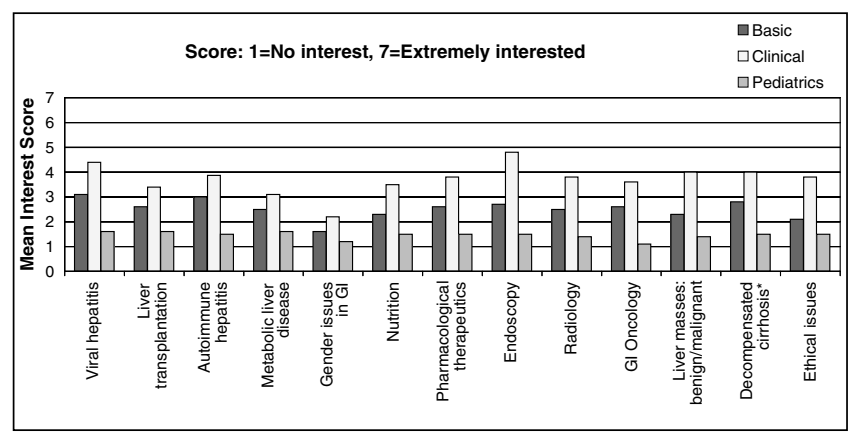

Figure 2) Mean interest score for potential scientific educational topics (topics 15 to 27). *Decompensated cirrhosis: ascites, varices, spontaneous bacterial peritonitis. GI Gastrointestinal

Examining respondents' primary role, 56\% were gastroenterologists, $6 \%$ identified hepatology as their focus, $3 \%$ were in pediatrics and $3 \%$ were surgeons. Basic and clinical scientists made up $13 \%$ and $1 \%$, respectively, of respondents. Residents accounted for $12 \%$, and "other" roles for $6 \%$.

Regarding where respondents spend their time, 71\% identified clinical practice as their primary focus, and $16 \%$ noted basic research. Teaching accounted for 3\%, with $10 \%$ reporting "other" duties.

\section{Educational topics}

The mean interest score for the 27 scientific educational topics, from the perspectives of basic science, clinical science and pediatrics, are shown in Figures 1 and 2. As in previous years, the highest mean interest score recorded (5.2) was for education in clinical IBD, followed closely by the mean interest score for clinical endoscopy (4.8). IBD continues to be the highest-scored topic within each of the categories of clinical, basic science and pediatrics, despite holding IBD clinical and basic science symposia at Canadian Digestive Diseases Week this past February. Clinical sessions on upper gastrointestinal bleeding and viral hepatitis (each scored as 4.4) were also much in demand. Mean scores for the remaining topics ranged from 2.2 to 4.2 for clinical topics, 1.6 to 4.1 for basic science topics and 1.1 to 2.3 for pediatrics.

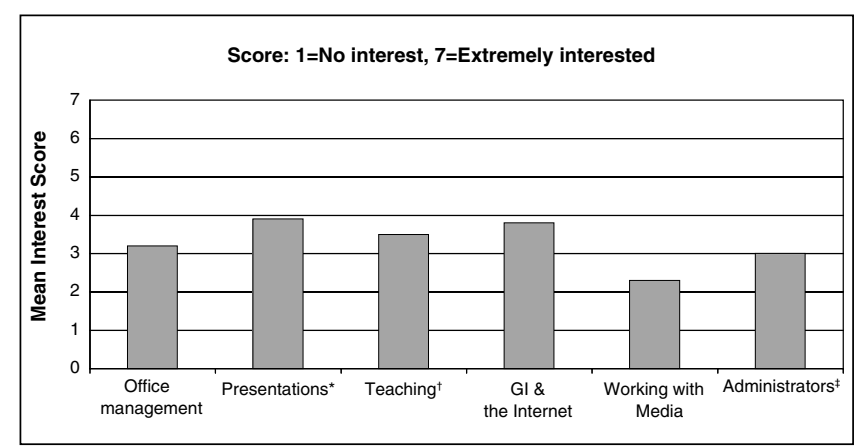

Figure 3) Mean interest score for potential educational topics (nonscientific). *Developing effective presentations; †Teaching theory and techniques; Dealing with administrators. GI Gastrointestinal

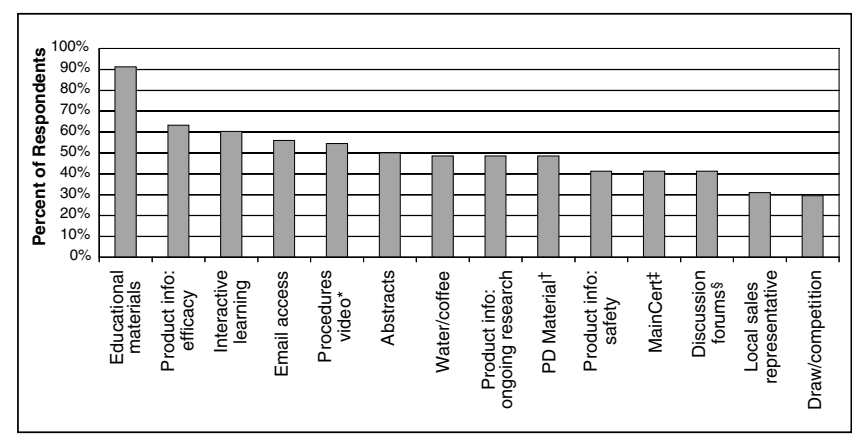

Figure 4) Needs for the exhibit area. *Video on endoscopy/ colonoscopy or other procedures; ${ }^{\dagger}$ Material for professional development; $¥$ Accredited (MainCert) personal learning objectives; $\S$ Discussion forums with key opinion leaders. PD Professional development

Responses for nonscientific educational event topics are given in Figure 3. The highest scores of 3.9 for "Developing effective presentations" and 3.8 for "GI and the internet" were still lower than the top-scored clinical topics.

\section{Exhibits}

Replies to the question "Which of the following would be most valuable to you in an exhibit area?" are shown in Figure 4. Respondents were allowed to select more than one item; thus, percentages do not sum to $100 \%$. The overwhelming favourite, selected by $91 \%$, was Educational Materials, with Product Information on Efficacy a distant second at 63\%.

\section{Interactive lecture series}

Forty-three per cent of respondents reported accessing the lecture series repeatedly, while $38 \%$ had never used the e-library (Figure 5).

\section{Online atlas of endoscopy}

The vast majority of respondents (90\%) agreed that, if available, they would use an online Canadian atlas of endoscopy (Figure 6).

\section{DISCUSSION}

It is disappointing that so few completed the needs assessment this year, with only $7.4 \%$ of the membership (68 individuals) participating. It is unlikely that this is related to the online 


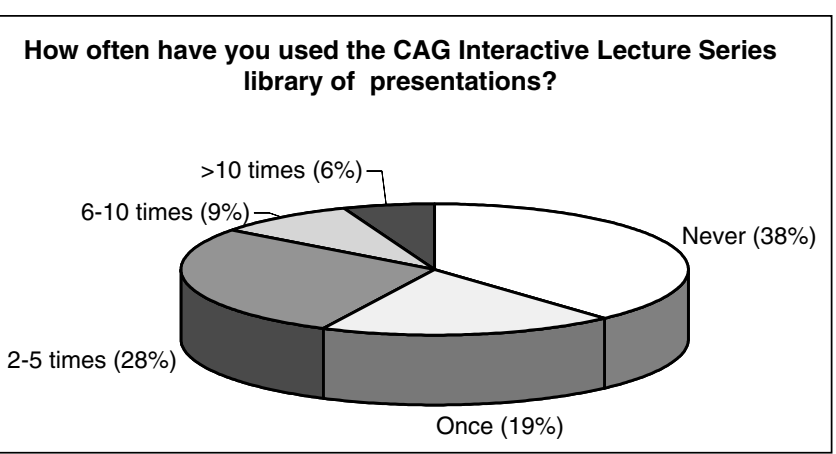

Figure 5) Use of the Canadian Association of Gastroenterology (CAG) Interactive Lecture Series library of presentations available online for use with CD-ROM

format given that last year's e-survey saw a 24\% (187 members) completion rate, comparable with paper-based surveys. It is possible that the low response was due to the knowledge that a Canadian Digestive Diseases Week will not be held in

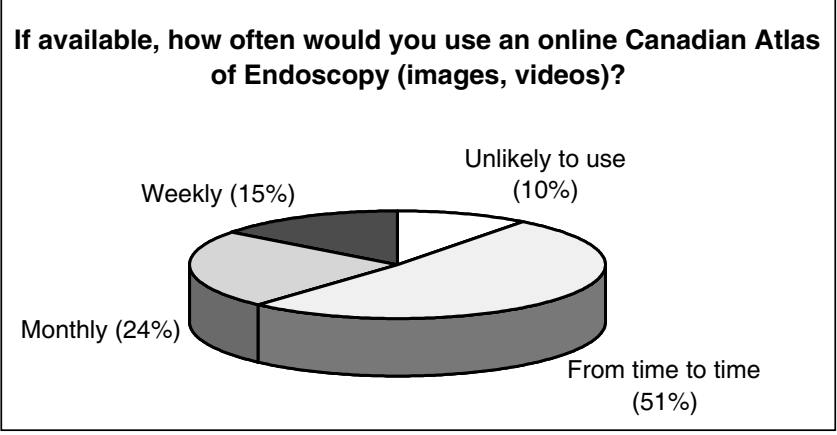

Figure 6) Anticipated use of an online Canadian atlas of endoscopy, if made available

2005, because the World Congress of Gastroenterology will take place in Montreal in September 2005. The results of this needs assessment should be interpreted with caution because they represent only a small portion of the membership. 


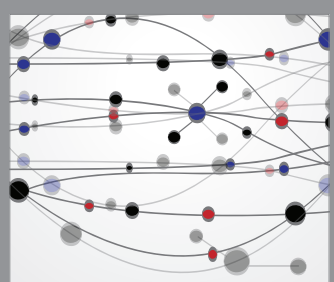

The Scientific World Journal
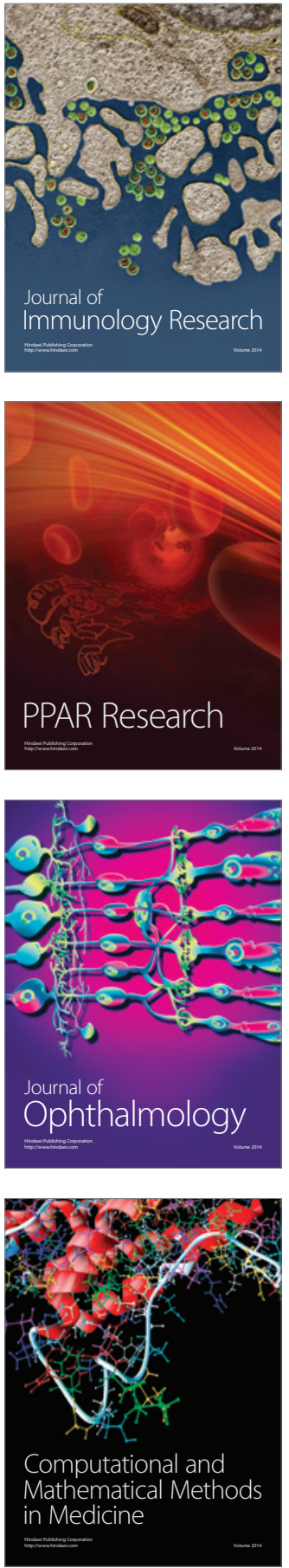

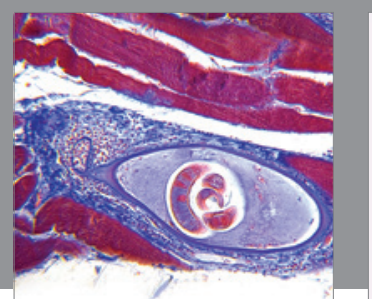

Gastroenterology Research and Practice

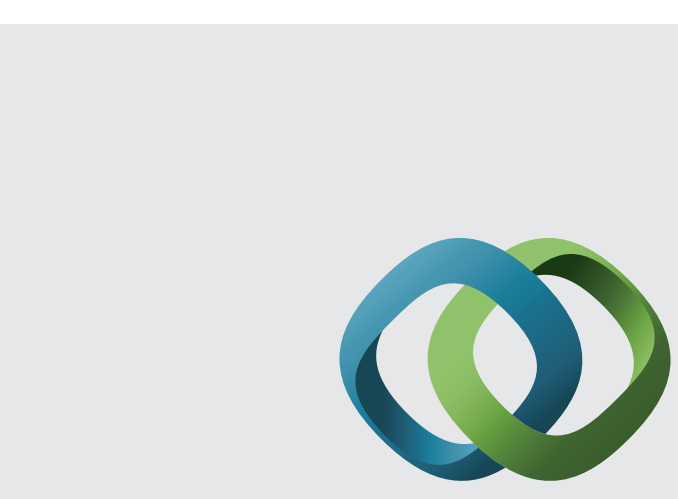

\section{Hindawi}

Submit your manuscripts at

http://www.hindawi.com
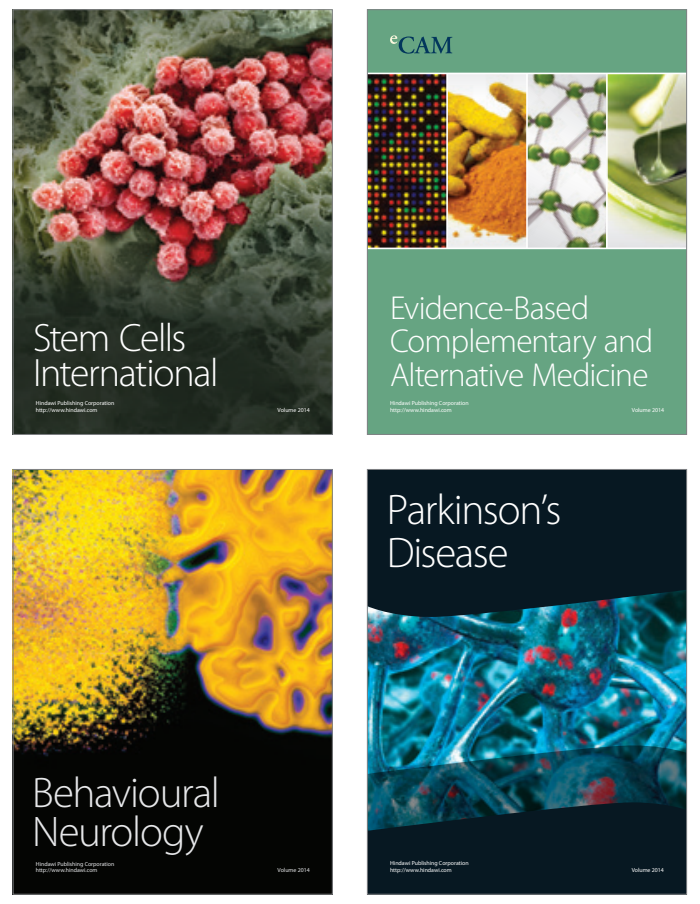
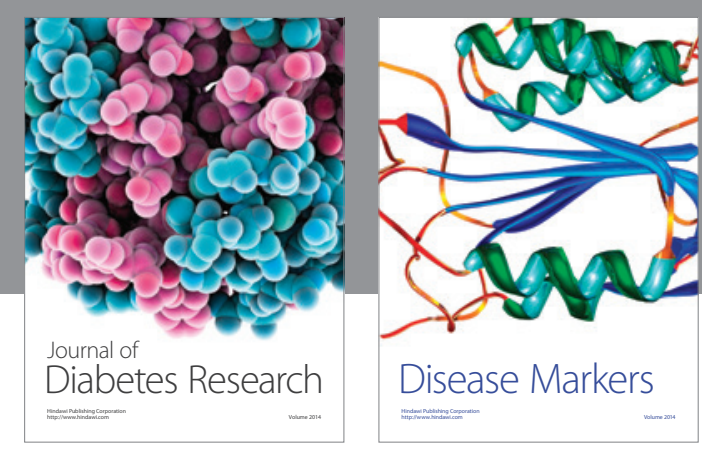

Disease Markers
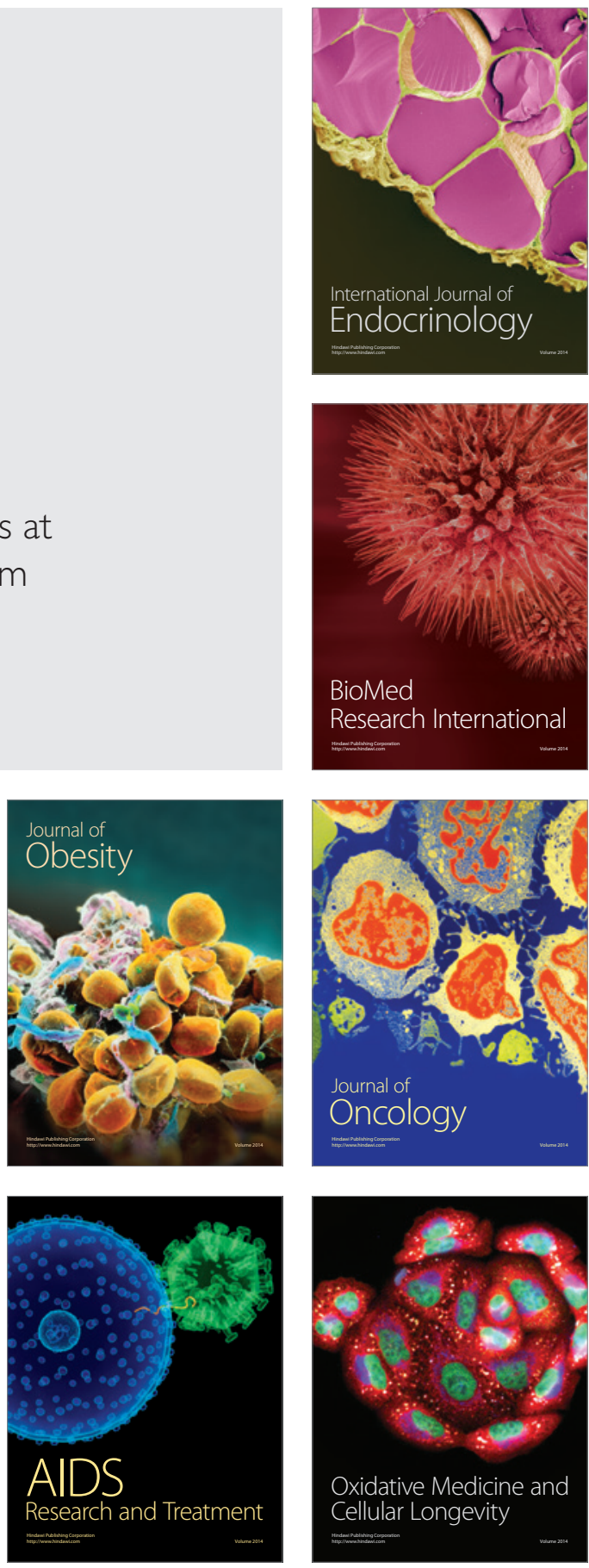